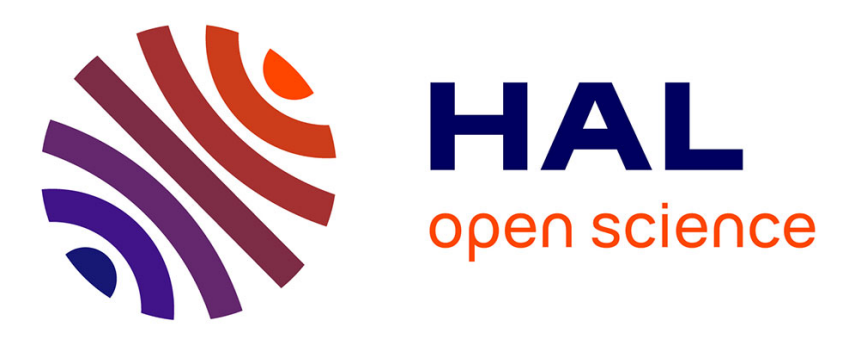

\title{
Teaching the basics of electricity using a flexible piezoelectric generator
}

\author{
Raynald Seveno, Thibault Dufay, Mohammed El Gibari, Benoit Guiffard, \\ Hong Wu Li, Saber Morsli, Aude Pichon, Eric Tanguy
}

\section{- To cite this version:}

Raynald Seveno, Thibault Dufay, Mohammed El Gibari, Benoit Guiffard, Hong Wu Li, et al.. Teaching the basics of electricity using a flexible piezoelectric generator. Physics Education, 2018, 53 (4), pp.045015. 10.1088/1361-6552/aabf27 . hal-01794929

\section{HAL Id: hal-01794929 \\ https://hal.science/hal-01794929}

Submitted on 7 Jun 2021

HAL is a multi-disciplinary open access archive for the deposit and dissemination of scientific research documents, whether they are published or not. The documents may come from teaching and research institutions in France or abroad, or from public or private research centers.
L'archive ouverte pluridisciplinaire HAL, est destinée au dépôt et à la diffusion de documents scientifiques de niveau recherche, publiés ou non, émanant des établissements d'enseignement et de recherche français ou étrangers, des laboratoires publics ou privés. 


\title{
Teach the basics of electricity by the use of a flexible piezoelectric generator.
}

\author{
R. Seveno, T. Dufay, M. El Gibari, B. Guiffard, H. W. Li, S. Morsli, A. Pichon and E. Tanguy \\ UFR des Sciences et des Techniques, Université de Nantes \\ 2 rue de la houssinière, 44322 cedex 03 , Nantes, France \\ raynald.seveno@univ-nantes.fr
}

\begin{abstract}
Lecturer-researchers, because of the duality of their profession, have the opportunity to introduce students directly to their research. Stimulating student interest through practical research topics enables students to see the relevance of the teaching/learning process and thereby enhances their motivation. As a major societal issue, research on renewable energies is held in great esteem, particularly among young students with a strong interest in environmental issues. The work presented here relates to the realization of a practical class on the testing of a flexible piezoelectric generator studied as part of the "N-air-J" regional research project. The particular characteristic of piezoelectric materials is that they produce electricity when compressed, which means that they can be used in energy recovery devices. The electrical model associated with this type of generator, consisting of an ideal current source in parallel with a linear capacitor and a load resistor, is sufficiently simple to be understood by first-year university students following a course on electricity. Using an appropriate mechanical excitation system (made out of Lego@), it is possible to generate variations in the quasi-sinusoidal compressions of a flexible piezoelectric film. By connecting an oscilloscope directly to the terminals of this experimental generator, students can visualize the produced current flowing through its input impedance, thus making it possible to use the laws of electrokinetics on an alternating sinusoidal current. As the objective of the practical class is to calculate the energy density produced by this type of generator, it uses the notions of Ohm's law, current dividers, equivalent resistances (serial/parallel associations), power and density of energy to provide concrete examples of some of the basics of electricity. High school students in year one of a science and laboratory technology baccalaureate in France have already taken this practical class as part of a dissemination campaign on scientific culture.
\end{abstract} laws

Keywords-piezoelectricity; basics of electricity; electrokinetics

\section{INTRODUCTION (HEADING 1)}

Thanks to the two facets of their profession, teacherresearchers have the opportunity to present their research themes in their lectures, since they generally teach in their favoured disciplines. However, if the presentation of research work in a Master's degree remains relatively easy, this is not the case for undergraduate courses, and especially for the first-year public who do not often have the necessary scientific background to understand cutting-edge research. Nevertheless, it is often at this time that students choose their core discipline, and it is important to pay particular attention to the teachings they receive. At present, research pertaining to renewable energies to address the shortage of fossil fuels is a subject of common interest. Indeed, young people are deeply concerned about environmental issues. A lot of research revolves around the development of generators that are able to convert ambient energies into electricity, such as canonical solar cells [1] and micro-power systems like electromagnetic [2] or electrostatic [3] generators.

In this paper, we present a practical session based on the Nair-J research project, the objective of which is to study the possibility of recovering energy from air currents using a synthetic blade of grass able to convert mechanical energy into electricity (principle of piezoelectricity). This generator consists of a piezoelectric thin film of lead zirconate titanate (PZT) $3 \mu \mathrm{m}$ thick, deposited by a Chemical Solution Deposition (CSD) process onto a $16 \mu \mathrm{m}$ thick aluminum foil [4]. An upper electrode of aluminum of $200 \mathrm{~nm}$ thick, evaporated by the Joule effect, makes it possible to obtain the piezoelectric capacitor. The last is then encapsulated by lamination into polyethylene terephthalate (PET, $150 \mu \mathrm{m})$ to make it flexible. During the lesson, the students will determine the piezoelectric coefficient $d_{31}$ of the PZT film, which makes it possible to evaluate the piezoelectric potential of the used generator. The students will then characterize the flexible piezoelectric generator using the laws of electrokinetics. This will provide them with a concrete case to apply the theoretical knowledge they have learned in class.

Initially, we interest the students by the presentation of the generator (Fig. 1), which looks like a simple piece of plastic. By connecting it directly to an oscilloscope, the students can see that an electrical signal of random shape is produced by manual folding of the generator (Fig. 2).

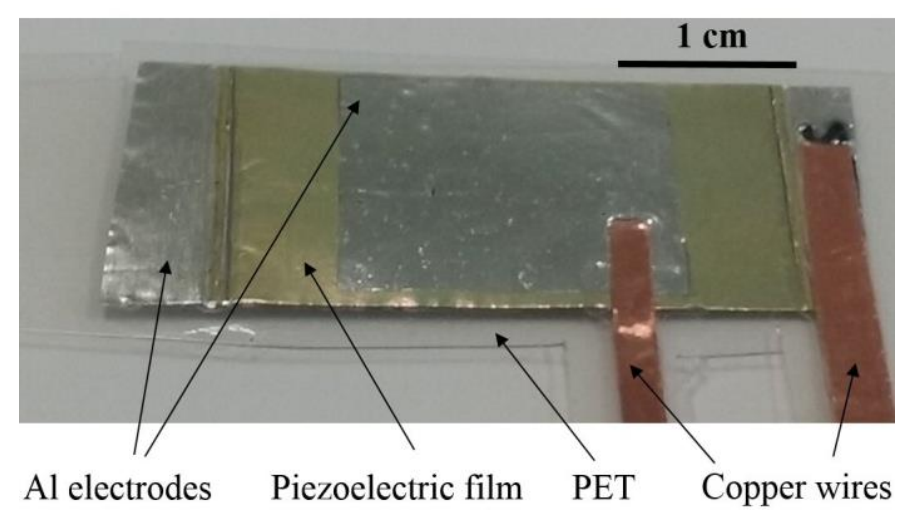

Figure 1. Photograph of the piezoelectric generator. 


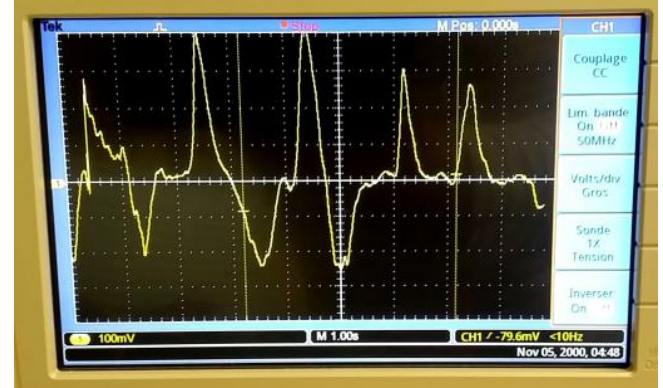

Figure 2 Photograph of the harvested random shape voltage.

Then, the principle of piezoelectricity is explained in a few words, as is the research carried out on the development of piezoelectric materials used for the conception of the generator studied during the practical class. How can one compare the piezoelectric materials with one another? How can we quantify the amount of electricity produced by this type of generator? What is the electrical power produced? The experiments in this lesson should be able to answer these questions.

\section{DETERMINATION OF THE PIEZOELECTRIC COEFFICIENT}

The first experiment consists in the determination of the piezoelectric coefficient $d_{31}$. Even if this coefficient is not directly related to the power delivered by the generator, it makes it possible to evaluate the piezoelectric ability of the material used to build the generator.

By applying an alternative electric voltage $v=$ $V_{0} \cos (2 \pi f)$ to an Al/PZT/Al cantilever beam, the latter oscillates at the same frequency $f$, due to the inverse piezoelectric effect. A laser vibrometer (Polytech OFV 2200) is then used to measure the tip deflection $d$ at the free end of the beam (Fig. 3). The students perform these measurements at different frequencies and have to fit the corresponding plots to the canonical model of an oscillating system under sinusoidal excitation (eq. 1), as already used in the $R L C$ circuit theory (Fig. 4).

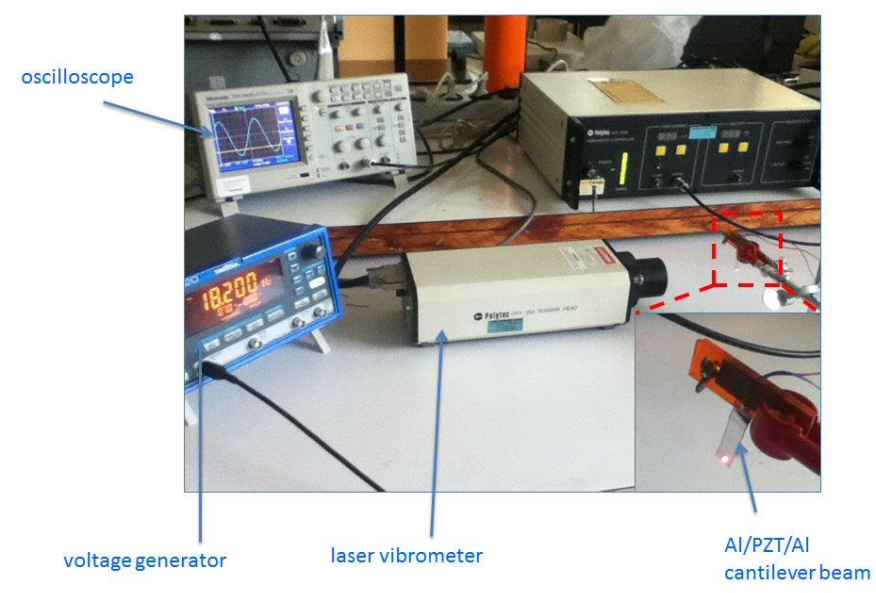

$d_{0}$ is the quasi-static displacement, $f_{0}$ is the resonance frequency of the oscillator in the free mode and $Q$ is the quality factor [5].

$$
d=d_{0} / \sqrt{\left(1-\left(\frac{f}{f_{0}}\right)^{2}\right)^{2}+\left(\frac{f}{f_{0 \times Q}}\right)^{2}}
$$

The fit of the plots allows the determination of the $d_{0}$ value, which is used for the calculation of the piezoelectric coefficient $d_{31}$ (eq.2), where the $\alpha$ constant depends on the structure of the cantilever (dimensions and Young's moduli) [6].

$$
d_{31}=\alpha \times d_{0} / V_{0}
$$

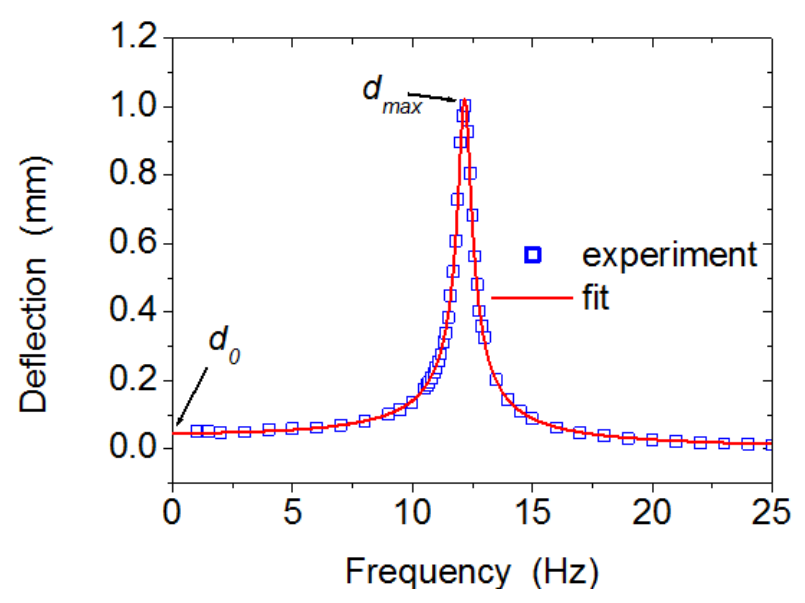

Figure 4. Tip deflection of the cantilever beam as a function of the frequency of the applied voltage and the associated fits.

\section{ENERGY HARVESTING MEASUREMENTS}

The piezoelectric generator is inserted into a mechanical excitation device (Fig. 5) able to generate a variation of quasisinusoidal deformation of the flexible generator, leading to a quasi-sinusoidal signal observed on the oscilloscope $u_{R}=$ $U_{R} \cos (2 \pi f t)$ (frequency $f$ of the signal is imposed by the motor speed of the mechanical excitation device), as shown in Fig. 6.

Students then realize that piezoelectric generators deliver alternative, not continuous, electricity. The measurement of the $U_{R}$ amplitude of the voltage observed at the terminals of the input impedance $(1 \mathrm{M} \Omega$ ) of the oscilloscope makes it possible to calculate the power thus delivered by the generator with the help of the formula given in the equation 3 .

$$
P=U_{R}^{2} / 2 R
$$

Figure 3. Photograph of the piezoelectric characterization device. 

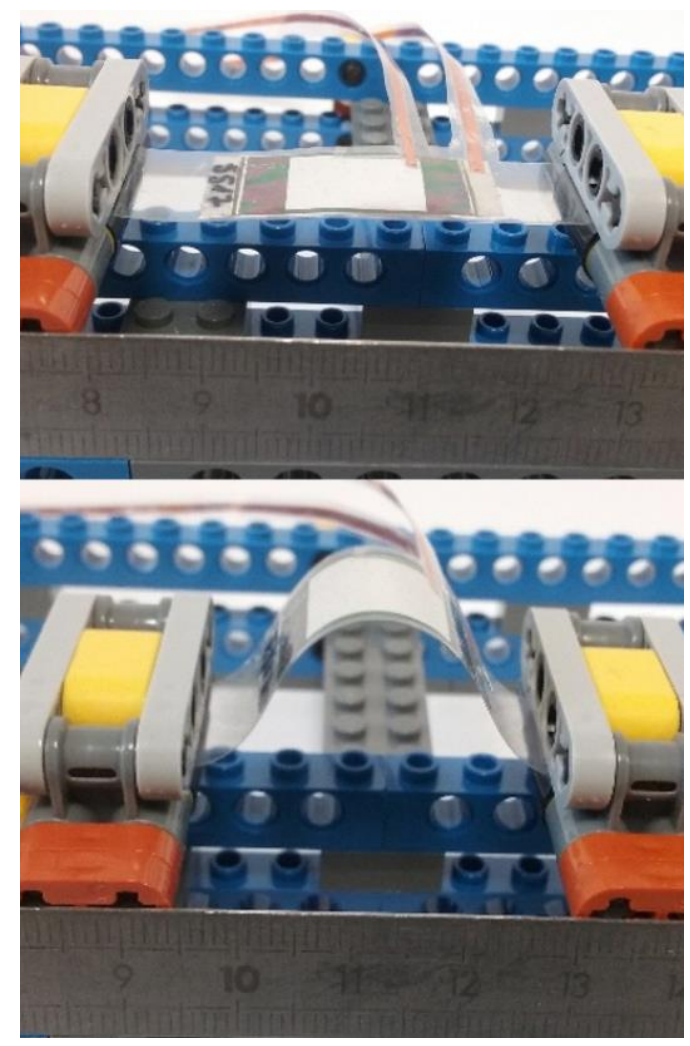

Figure 5. Photograph of the bending device.

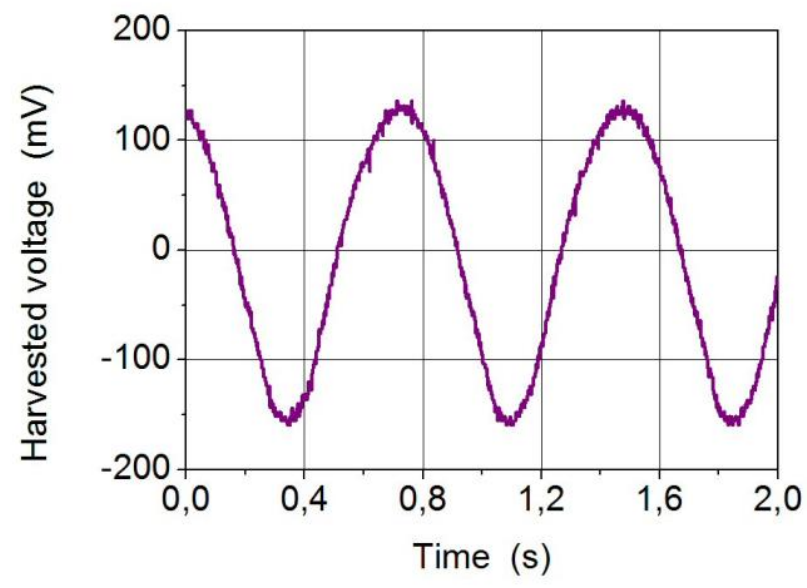

Figure 6. Output voltage of the piezoelectric harvesting device.

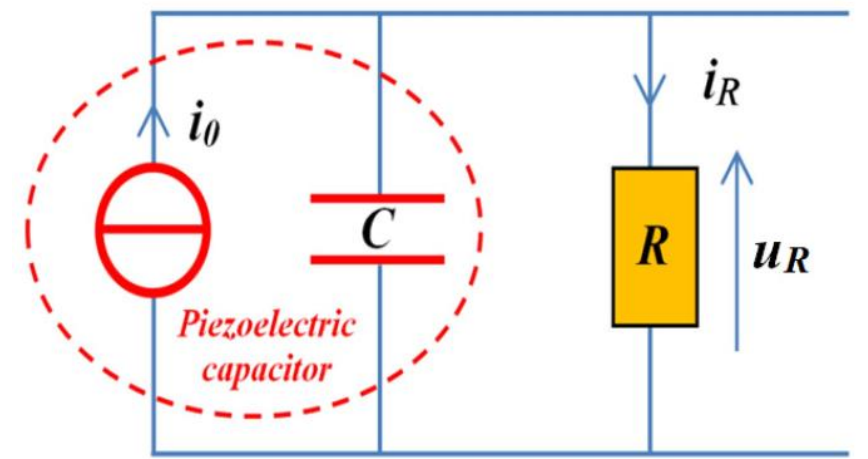

Figure 7. Scheme of the equivalent circuit of the piezoelectric harvesting device.

Important questions are: Is this power optimal? Can the device be improved to increase the level of power recovered? To answer these questions, the students must study the equivalent circuit corresponding to the assembly (Fig. 7). The piezoelectric generator is modeled by an ideal current generator $i_{0}$ associated in parallel with a linear capacitance $C$. The input impedance of the oscilloscope is represented by a load resistor $R$ connected in parallel to the generator. This resistance is modifiable by experimentally adding a resistance in parallel to the circuit.

At a fixed frequency $f(\omega=2 \pi f)$, the students perform different measurements of the amplitude of the voltage $U_{R}$ by modifying the value of the load resistor $R$. To do this, they insert resistor associations in parallel with the circuit and need to use the equivalence resistance formula to compute the new values of $R$. Using the formula in equation 3, the Ohm's law (eq.4) and the formula of the current divider bridge (eq.5), Students can fit the experimental values of the $\left(U_{R} ; I_{R} ; P\right)=f(R)$ curves and thus determine the value of the piezoelectric current's amplitude $I_{0}$, also called the short-circuit current (Fig. 8). Error bar of the voltage has been determined at the oscilloscope, and the students calculate the corresponding error bars of current and power.

$$
U_{R}=R \times I_{R} \text { (4) } I_{R}=I_{0} / \sqrt{1+R^{2} C^{2} \omega^{2}}
$$

The amplitude of the open-circuit voltage $U_{O C}$, another intrinsic property of the generator, is obtained by causing the load resistor $R$ to tighten to infinity, and is given by the equation 6 :

$$
U_{O C}=I_{0} / C \omega
$$




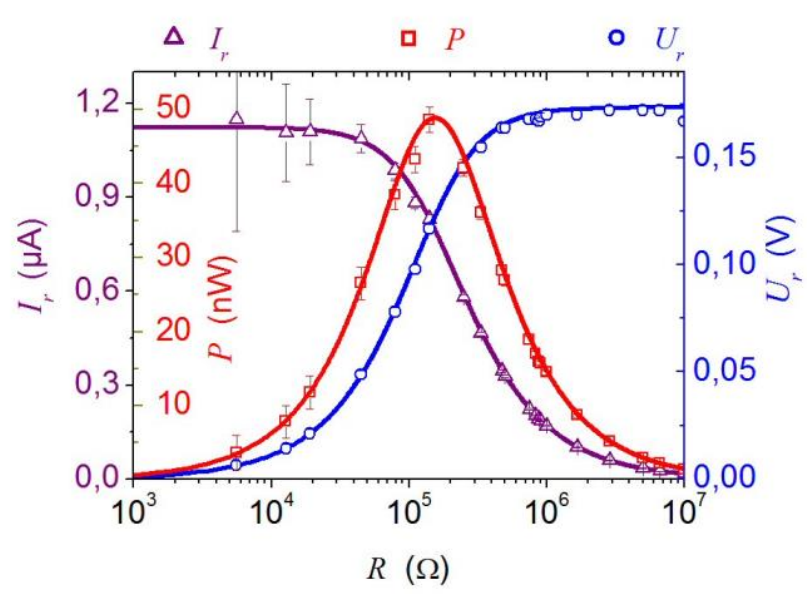

Figure 8. Amplitude of the current and voltage across the resistive load resistor $R$ and the harvested power as a function of $R$.

In addition to the generator characteristics $I_{0}$ and $U_{o c}$ that are clearly legible on the curves, students may notice that the power passes through a maximum for a given resistance $R_{\text {opt }}$. They are then asked to recover the theoretical value $R_{\text {opt }}=1 / C \omega$ of this resistance by solving the equation $\frac{d P}{d R}=0$.

By injecting the $R_{\text {opt }}$ value into the expression of $P=f(R)$, we obtain the maximum value of the harvested power (eq.7).

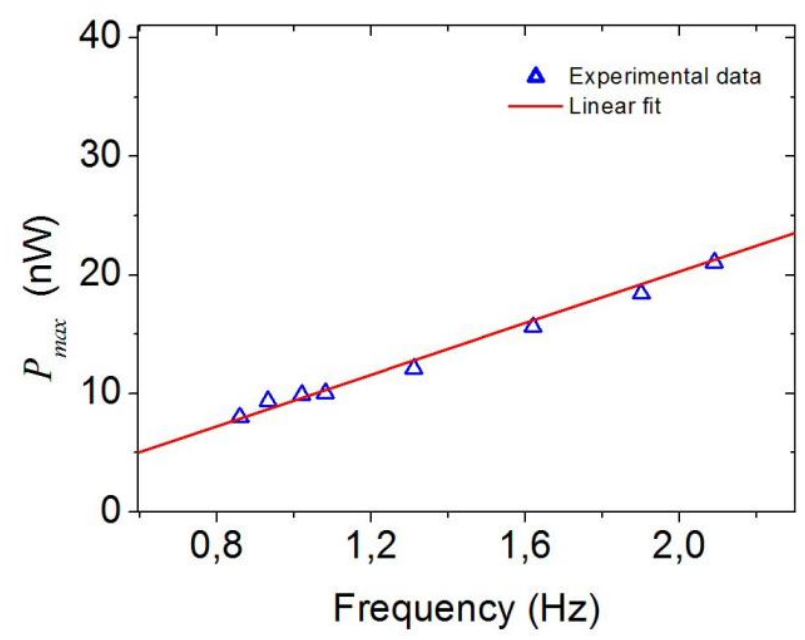

Figure 9. Amplitude of the output power at the optimal load resistor as function of the frequency of the applied mechanical excitation.

$$
P_{\max }=I_{0}^{2} / 4 C \omega
$$

To optimize the precision of the calculated values of the intrinsic properties of the generator, the students repeat the measurements at different frequencies, thus making it possible to plot the curve $P_{\max }=g(f)$ as shown in Fig. 9. They notice that the maximum power $P_{\max }$ value is proportional to the excitation frequency. A linear regression is then required, and the obtained slope coefficient $\beta$ is used for the calculation of the energy density $E_{S}=\beta / V$, where $V$ is the volume of the piezoelectric capacitor.

\section{FEEDBACK OF STUDENTS}

In the context of a dissemination campaign on scientific culture ("Passeport recherche"), 20 high school students in year one of a science and laboratory technology baccalaureate in France have taken this practical class (only the harvesting voltage part, not the determination of the piezoelectric coefficient). At the beginning of the school year, they had to choose between different subjects of scientific studies, and chose, along with their teachers, to work on the $\mathrm{N}$-air-J project. Initially, two researchers from this project went to give an oral presentation to students in their high school. They introduced the context and objectives of the project, and explained the principle of piezoelectricity, which is the basis of the operation of the generators studied. Secondly, the students came to the science faculty of Nantes (France) to carry out a practical work on the piezoelectric generator, as described in

Several weeks after doing the practical class, the students have answered to an anonymous survey. For each questions, they had to give a note ranging from 1 to 5 representing their agreement to the question (1: disagree; 5: totally agree). Results of the survey, including number of students who give the corresponding note and the average note per each question, are given in Table 1. Generally, the students did appreciate to experiment flexible piezoelectric generator and most of them understood the utility of the theoretical model to characterize the generator. However, they are not accustomed to fit experimental plots with formula, and the level of the practical session seems to be a little bit high for high school students.

\section{CONCLUSION}

Based on the research developed in the $\mathrm{N}$-air-J project, a practical session has been build, in which a flexible piezoelectric generator is characterized. The production of a quasi-sinusoïdal voltage observable at an oscilloscope allows the students to apply theoretical knowledges, as resonance phenomenon of an oscillator, calculation of equivalent resistances, Ohm's law and current dividers. They fit the experimental plots to the electrokinetic's laws to determine the generator's properties. Through this experience, they access to actual researches and can directly apply the basics of electricity in a concrete case. 
Table 1. Results of the anonymous survey

\begin{tabular}{|c|c|c|c|c|c|c|}
\hline & 1 & 2 & 3 & 4 & 5 & Note /5 \\
\hline $\begin{array}{l}\text { Does the renewable energies' topic influence your } \\
\text { choice of the study's project? }\end{array}$ & 2 & 6 & 6 & 5 & 1 & 2.9 \\
\hline $\begin{array}{l}\text { Does the research's project motivate you to learn } \\
\text { electricity? }\end{array}$ & 2 & 7 & 4 & 7 & 0 & 2.8 \\
\hline $\begin{array}{l}\text { Does the research's project allow to identify a real case } \\
\text { of applied electricity? }\end{array}$ & 1 & 2 & 7 & 7 & 3 & 3.5 \\
\hline $\begin{array}{l}\text { Does the experimental course illustrate the research's } \\
\text { project? }\end{array}$ & 1 & 7 & 5 & 3 & 4 & 3.1 \\
\hline $\begin{array}{l}\text { Is the experimental course helpful to understand the } \\
\text { interest of a theoretical model to study electricity? }\end{array}$ & 0 & 4 & 10 & 4 & 2 & 3.2 \\
\hline $\begin{array}{l}\text { Is the experimental course helpful to understand the } \\
\text { interest the basics of electricity? }\end{array}$ & 3 & 4 & 4 & 7 & 2 & 3.1 \\
\hline
\end{tabular}

\section{AKNOWLEDGMENT}

The authors would like to thanks P. Derval, S. Hassini, B. Masse and P. Navaro for their contribution to the build of the practical session. They thank A. Cheillan and T. Morisseau, and all the students of their group from Alcide d'Orbigny high school (Bouaye, France), to their participation to the $\mathrm{N}$-air-J project and its dedicated practical session. The N-air-J project is supported by the French region Pays de la Loire through the 201407965 contract.

\section{REFERENCES}

[1] D. Wang, M. Wright, N. K. Elumalai, and A. Uddin, « Stability of perovskite solar cells », Sol. Energy Mater. Sol. Cells, vol. 147, p. 255-275, 2016.

[2] I. Sari, T. Balkan, and H. Külah, « An Electromagnetic Micro Power Generator for Low-Frequency Environmental Vibrations Based on the Frequency Upconversion Technique », J. Microelectromechanical Syst., vol. 19, n ${ }^{\circ} 1$, p. 14-27, 2010.

[3] F. Peano and T. Tambosso, « Design and optimization of a MEMS electretbased capacitive energy scavenger », J. Microelectromechanical Syst., vol. 14, no 3, p. 429-435, 2005.

[4] R. Seveno and D. Averty, « Ultra light tunable capacitor based on PZT thin film deposited onto aluminium foil », J. Sol-Gel Sci. Technol., vol. 68, n ${ }^{\circ}$ 2, p. $175-179,2013$.

[5] F. K. Kneubühl, "Oscillations and waves”, Springer, ISBN 3-540-62001X, 114, 2007.

[6] P. Luginbuhl et al, Sensors and Actuators A, 54, 530, 1996. 